\title{
Risk-based approach to develop a national residue program: prioritizing the residue control of veterinary drugs in fishery products
}

\author{
Hui-Seung Kang ${ }^{1 *}$ D, Songyi Han², Byung-Hoon Cho ${ }^{1}$ and Hunjoo Lee ${ }^{3^{*}}$
}

\begin{abstract}
Veterinary drugs are widely used to protect production-related diseases and promote the growth of farmed fish. The use of large amounts of veterinary drugs may have potential risk and cause adverse effects on both humans and the environment. In this study, we developed risk-based ranking based on a scoring system to be applied in the national residue program. In this approach, the following three factors of veterinary drugs that may occur as residues in fishery products were considered: potency (acceptable daily intake), usage (number of dose and withdrawal period), and residue occurrence. The overall ranking score was calculated using the following equation: potency $\times$ usage (sum of the number of sales and withdrawal period) $\times$ residue occurrence. The veterinary drugs that were assigned high score by applying this approach were enrofloxacin, amoxicillin, oxolinic acid, erythromycin, and trimethoprim. The risk-based approach for monitoring veterinary drugs can provide a reliable inspection priority in fishery products. The developed ranking system can be applied in web-based systems and residuemonitoring programs and to ensure safe management of fishery products in Korea.
\end{abstract}

Keywords: Risk, Priority, Veterinary medicine, Inspection, Fishery products

\section{Background}

Aquatic products are a major food resource with a lowcost and high-efficiency productivity, and farmed fish production have been continuously increasing (Kim et al. 2010; Kim et al. 2014). In Korea, seafood consumption per capita was approximately $60 \mathrm{~kg}$ in 2014-2016, maintaining the highest level of fishery product consumption in the world (FAO 2016). To meet the demand for fish and crustaceans, most of them are produced under dense farming conditions, which can be a stress factor and increase the possibility of disease prevalence (Uchida et al. 2016). Thus, the authorized veterinary drugs such as antibiotics and anthelmintics have been continuously used to prevent diseases in fishery

\footnotetext{
* Correspondence: hskang1235@korea.kr; adstar@cheminet.kr

${ }^{1}$ Pesticide and Veterinary Drugs Residue Division, National Institute of Food and Drug Safety Evaluation, Osong, Cheongju, Chungcheongbuk-do 361-709, Republic of Korea

${ }^{3}$ CHEM.I.NET Ltd., Room 302, 773-3, Mok-dong, Yangcheon-gu, Seoul, South Korea

Full list of author information is available at the end of the article
}

farm (Kim et al. 2019). However, overuse or noncompliance of withdrawal period of veterinary drugs has been increasing due to the shift in farming environment such as changes in climate and incidence of antibiotic resistant bacteria (Kang et al. 2018).

An analysis of the sales of antimicrobials in animal husbandry and fish farm by the Korea Animal Health Products Association (KAHPA) revealed that approximately 1000 tons of antimicrobials was sold each year during 2011-2015. The highest volume of antimicrobials was sold for use in pigs farms $(53 \%, 481$ tons) followed by fishery (22\%, 201 tons), poultry (17\%, 157 tons), and cattle industries (8\%, 71 tons) (KAHPA 2019; Lee et al. 2018). As a large amount and several kinds of veterinary drugs are used yearly, useful tools are needed to develop more effective risk management strategies under limited budget of governmental authorities (Kang et al. 2019). The Irish government has developed a national residue program for effective prioritization residue evaluation and sampling plan such as veterinary drugs and 
pesticides in livestock products. The risk-based approach is applied in the national residue program to determine the prioritization of veterinary drugs through ranking system based on risk factors such as potency, usage, and residue occurrence (Danaher et al. 2016). The ranking system reflects the factors considering the risk through a simplified model for prioritization of compounds to save cost and time. Thus, similar ecological models have been proposed in other countries for the management of veterinary drugs. Indeed, Italy has developed the priority model "RANKVET" considering 48 veterinary drug residue occurrences in environment compartments to assess the potential risks (Di Nica et al. 2015). Portugal applies prioritization based on antibiotic usage, ecosystem exposure, and antibiotic metabolism in livestock and humans (Almeida et al. 2014).

Global regulatory authorities have established the maximum residue limits (MRLs) for veterinary drugs in animal products to protect potential human health effect. The Korean Ministry of Food and Drug Safety sets the MRLs for 55 veterinary drugs in fishery products, and 18 substances are managed as prohibited substances in consideration of their carcinogenicity and genotoxicity (MFDS 2019). However, risk-based priority study to support national residue inspection remains still limited in Korea. In this study, we classified three factors that can evaluate the risk for effective management of veterinary drugs used in fishery products: (1) potency, (2) usage, and (3) residue occurrence. We then collected data and assigned scores according to each indicator. Our results of risk-based prioritization can be applied to the safety management of veterinary drugs and the establishment of domestic inspection sampling plans in aquatic animal products.

\section{Methods}

\section{Prioritization model}

In previous studies, most of the priority models and systems have been applied in eco-surveillance. Thus, to prioritize veterinary drugs used in fishery products, a priority equation based on risk-based approach in domestic animal production by the Food Safety Authority Ireland (FSAI) was used. The collected data, the coded data, and the score were applied in the following equation. Based on the calculated scores, the substances were classified into four groups according to the quartiles.

$$
\text { Priority }_{\mathrm{r}}=\mathrm{P}_{\mathrm{r}} \times \mathrm{U}_{\mathrm{r}} \times \mathrm{R}_{\mathrm{r}, \mathrm{f}}
$$

where Priority ${ }_{\mathrm{r}}$ is the risk-based predicted priority of veterinary drugs in fishery products,

$P_{r}$ is the ADI of veterinary drugs, $U_{r}$ is the usage (number of sales + withdrawal period), and $R_{r, f}$ is the residue occurrence (detection rate + noncompliant sample number).

\section{Sample selection and data collection}

Taking into consideration the detection characteristics, the substances were selected (Table 1). In terms of the selected veterinary drugs, data on $\mathrm{ADI}$, number of veterinary drug sales (usage), withdrawal period of veterinary drugs in fishery products, and veterinary drug residue occurrence in fishery products (detection rate, noncompliant history) were collected.

\section{Compilation of data for risk analysis}

To select the priority of test samples, the classification criteria were divided into three categories as follows and coded, and the priority was determined by scoring.

1) Potency $\left(P_{r}\right)$ : ADI was used as a basic data for assessing the safety of veterinary drugs for risk-based prioritization. The data provided by the European Medicine Agency (EMA) and FAO/WHO Joint Expert Committee of Food Additives (JECFA) were utilized as the ADI used in this study.

2) Usage $\left(U_{r}\right)$ : The number of sales was calculated based on the Korea Animal Health Product Association's 2013 statistics (KAHPA 2019). The withdrawal period was used in the veterinary drug guidebook for fishery products presented by National Institute of Fisheries and Science (NIFS 2016).

3) Residue occurrence $\left(R_{r, f}\right)$ : It was calculated based on the research data conducted by the National Institute of Food and Drug Safety Evaluation in 2014-2016 (Kang et al. 2018; Shin et al. 2018). In addition, the number of noncompliant sample and detection rate were utilized for the residue occurrence.

\section{Ranking for prioritization}

The collected data were scored by dividing the data on the potency, usage, and residual level into four classes to prioritize the veterinary drugs used in fishery products. For easy substitution in the calculated equation, the scores were assigned up to 4 points.

1) The potency was calculated based on the ADI. The ADI was scored as $0.1<, 0.01-0.1,0.001-0.01$, and $<$ $0.001 \mathrm{mg} / \mathrm{kg}$ bw/day. When there was no ADI, it was calculated based on the maximum score.

2) The usage was calculated by dividing the number of sales and withdrawal period of the veterinary drugs, scoring them, and adding the scores. The unit of dose was $\mathrm{kg}$, and it was assigned scores as follows: high $(10,000 \mathrm{~kg}$ or more), middle (1000-10,000 kg), low $(1-1000 \mathrm{~kg})$, and very low $(<1 \mathrm{~kg})$. The withdrawal period was assigned scores as follows: 
Table 1 Target veterinary drugs and their MRL in fishery products by the Food Code

\begin{tabular}{|c|c|c|}
\hline Class & Compound & $\operatorname{MRL}(\mathrm{mg} / \mathrm{kg})$ \\
\hline \multirow[t]{3}{*}{ Amphenicols } & Florfenicol & $0.2^{\mathrm{b}}$ \\
\hline & Florfenicol amine & $0.2^{b}$ \\
\hline & Thiamphenicol & 0.05 \\
\hline \multirow[t]{3}{*}{ Cephalosporins } & Cefalexin & 0.2 \\
\hline & Ceftiofur & n... ${ }^{a}$ \\
\hline & Desfuroyl Ceftiofur & n.a. \\
\hline \multirow[t]{9}{*}{ Quinolones } & Ciprofloxacin & $0.1^{b}$ \\
\hline & Difloxacin & 0.3 \\
\hline & Enrofloxacin & $0.1^{b}$ \\
\hline & Flumequine & 0.5 \\
\hline & Nalidixic acid & 0.03 \\
\hline & Norfloxacin & n.a. \\
\hline & Ofloxacin & n.a. \\
\hline & Oxolinic acid & 0.1 \\
\hline & Pefloxacin & n.a. \\
\hline \multirow[t]{6}{*}{ Macrolides } & Clindamycin & 0.1 \\
\hline & Erythromycin & 0.2 \\
\hline & Josamycin & 0.05 \\
\hline & Kitasamycin & 0.2 \\
\hline & Lincomycin & 0.1 \\
\hline & Spiramycin & 0.2 \\
\hline \multirow[t]{2}{*}{ Penicillins } & Amoxicillin & 0.05 \\
\hline & Ampicillin & 0.05 \\
\hline Pleuromutilins & Tiamulin & 0.1 \\
\hline \multirow[t]{16}{*}{ Sulfonamides ${ }^{c}$} & Sulfachlorpyrazine & 0.1 \\
\hline & Sulfachlorpyridazine & 0.1 \\
\hline & Sulfadiazine & 0.1 \\
\hline & Sulfadimethoxine & 0.1 \\
\hline & Sulfadoxine & 0.1 \\
\hline & Sulfaguanidine & 0.1 \\
\hline & Sulfamerazine & 0.1 \\
\hline & Sulfamethazine & 0.1 \\
\hline & Sulfamethoxazole & 0.1 \\
\hline & Sulfamethoxypyridazine & 0.1 \\
\hline & Sulfamonomethoxine & 0.1 \\
\hline & Sulfaphenazole & 0.1 \\
\hline & Sulfaquinoxaline & 0.1 \\
\hline & Sulfathiazole & 0.1 \\
\hline & Sulfisoxazole & 0.1 \\
\hline & Trimethoprim & 0.05 \\
\hline \multirow[t]{4}{*}{ Tetracyclines } & Chlortetracycline & $0.2^{\mathrm{b}}$ \\
\hline & Doxycycline & 0.05 \\
\hline & Oxytetracycline & $0.2^{b}$ \\
\hline & Tetracycline & $0.2^{b}$ \\
\hline \multirow[t]{2}{*}{ Others } & Ormethoprim & 0.1 \\
\hline & Praziquantel & 0.02 \\
\hline
\end{tabular}

${ }^{\text {aNon-applicable }}$

${ }^{b} M R L$ is given for the sum of the parent drug and its metabolite or epimer ${ }^{c} M R L$ is given for the sum of sulfonamides not set, $50-100$ days, $10-50$ days, and 10 days or less.

3) The residue occurrence was calculated based on the number of noncompliant samples and detection rate. The frequency of noncompliant samples with respective Korean MRL values was assigned scores as follows: 5 times or more, $3-5$ times, $1-2$ times, and zero. The detection rate of each veterinary drug in aquatic animals was assigned scores as follows: $1 \%$ or higher, $0.1-1 \%, 0.01-0.1 \%$, and $<0$.

\section{Results and discussion}

Data collection of veterinary drugs

The target veterinary drugs with set MRLs were selected as study substances (Table 1). To determine risk-based priorities for the target drugs, five indicators (viz., ADI, number of sales, withdrawal period, number of noncompliant samples, and detection rate) were selected, and the scores of 1-4 were assigned to each indicator (Tables 2 and 3). Priority ${ }_{\mathrm{r}}$ is described in the Methods. Priority $_{\mathrm{r}}$ was calculated based on the calculated scores and classified into four groups based on the quartiles of the scores. Ten substances were assigned the $75^{\text {th }}$ or

Table 2 Scoring categories for risk-ranking of veterinary drugs in fishery products

\begin{tabular}{|c|c|c|}
\hline Parameter & Score & Description \\
\hline \multicolumn{3}{|l|}{ Potency $\left(P_{r}\right)$} \\
\hline \multirow[t]{4}{*}{ Acceptable daily intake } & 1 & $>0.1$ mg kg-1 bw day-1 \\
\hline & 2 & $0.01-0.1$ mg kg-1 bw day-1 \\
\hline & 3 & $0.001-0.01 \mathrm{mg} \mathrm{kg}-1$ bw day- 1 \\
\hline & 4 & $<0.001$ mg kg-1 bw day-1 \\
\hline \multicolumn{3}{|l|}{ Usage $\left(U_{r}\right)$} \\
\hline \multirow[t]{4}{*}{ Number of sales } & 1 & $<0$ (very low) \\
\hline & 2 & 1-1000 (low) \\
\hline & 3 & 1000-10,000 (medium) \\
\hline & 4 & $>10,000$ (high) \\
\hline \multirow[t]{4}{*}{ Withdrawal Period } & 1 & $<10$ days \\
\hline & 2 & $10-50$ days \\
\hline & 3 & 50-100 days \\
\hline & 4 & - \\
\hline \multicolumn{3}{|l|}{ Residue occurrence $\left(R_{r, f}\right)$} \\
\hline \multirow[t]{4}{*}{ Noncompliant samples } & 1 & Zero \\
\hline & 2 & One or two \\
\hline & 3 & Three to five \\
\hline & 4 & Greater than five \\
\hline \multirow[t]{4}{*}{ Detection rate } & 1 & $<0 \%$ \\
\hline & 2 & $0-0.1 \%$ \\
\hline & 3 & $0.1-1 \%$ \\
\hline & 4 & $>1 \%$ \\
\hline
\end{tabular}


Table 3 Overall-rank coding and scoring of veterinary drugs in aquatic products

\begin{tabular}{|c|c|c|c|c|c|c|c|c|c|c|}
\hline Substance & $\begin{array}{l}\mathrm{ADI} \\
(\mathrm{mg} / \\
\mathrm{kg})\end{array}$ & $\begin{array}{l}\text { ADI } \\
\text { Rank }\end{array}$ & $\begin{array}{l}\text { Number } \\
\text { of Sales } \\
(\mathrm{kg})\end{array}$ & $\begin{array}{l}\text { Number } \\
\text { of sales } \\
\text { rank }\end{array}$ & $\begin{array}{l}\text { Withdrawal } \\
\text { period } \\
\text { (days) }\end{array}$ & $\begin{array}{l}\text { Withdrawal } \\
\text { period (days) } \\
\text { rank }\end{array}$ & $\begin{array}{l}\text { Number of } \\
\text { noncompliant } \\
\text { samples }\end{array}$ & $\begin{array}{l}\text { Number of } \\
\text { noncompliant } \\
\text { samples rank }\end{array}$ & $\begin{array}{l}\text { Detection } \\
\text { rate }\end{array}$ & $\begin{array}{l}\text { Detection } \\
\text { rate rank }\end{array}$ \\
\hline Amoxicillin & 0.002 & 3 & 112,021 & 4 & 20 & 2 & 4 & 3 & 0.88 & 3 \\
\hline Ampicillin & 0.003 & 3 & 37,359 & 4 & 20 & 2 & 0 & 1 & 0 & 1 \\
\hline Cefalexin & 0.5 & 1 & 656 & 2 & 5 & 1 & 0 & 1 & 0 & 1 \\
\hline Ceftiofur & 0.02 & 2 & 7308 & 3 & - & 4 & 0 & 1 & 0.07 & 2 \\
\hline Chlortetracycline & 0.03 & 2 & 75,454 & 4 & - & 4 & 0 & 1 & 0.07 & 2 \\
\hline Ciprofloxacin & 0.002 & 3 & 0 & 1 & - & 4 & 0 & 1 & 3.82 & 4 \\
\hline Clindamycin & 0.03 & 2 & 600 & 2 & 15 & 2 & 0 & 1 & & 1 \\
\hline Difloxacin & 0.01 & 3 & - & 1 & - & 4 & 0 & 1 & & 1 \\
\hline Doxycycline & 0.003 & 3 & 1553 & 3 & - & 4 & 0 & 1 & & 1 \\
\hline Enrofloxacin & 0.002 & 3 & 40,668 & 4 & - & 4 & 7 & 4 & 11.61 & 4 \\
\hline Erythromycin & 0.0007 & 4 & 6671 & 3 & 30 & 3 & 0 & 1 & 0.22 & 3 \\
\hline Florfenicol & 0.01 & 3 & 63,815 & 4 & 14 & 2 & 0 & 1 & 0.44 & 3 \\
\hline Flumequine & 0.03 & 2 & 2704 & 3 & 8 & 1 & 0 & 1 & 0.44 & 3 \\
\hline Josamycin & 0.002 & 3 & 0 & 1 & - & 4 & 0 & 1 & & 1 \\
\hline Kitasamycin & 0.5 & 1 & 572 & 2 & - & 4 & 0 & 1 & & 1 \\
\hline Lincomycin & 0.03 & 2 & 7300 & 3 & 10 & 2 & 0 & 1 & 0.07 & 2 \\
\hline Nalidixic acid & 0.002 & 3 & 0 & 1 & - & 4 & 0 & 1 & 0.51 & 3 \\
\hline Norfloxacin & - & 4 & 0 & 1 & - & 4 & 0 & 1 & & 1 \\
\hline Ofloxacin & - & 4 & 0 & 1 & - & 4 & 0 & 1 & & 1 \\
\hline Ormethoprim & 0.1 & 2 & - & 1 & - & 4 & 0 & 1 & 0.29 & 3 \\
\hline Oxolinic acid & 0.0025 & 3 & 6349 & 3 & 28 & 3 & 1 & 2 & 2.79 & 4 \\
\hline Oxytetracycline & 0.03 & 2 & 191,780 & 4 & 30 & 3 & 0 & 1 & 7.71 & 4 \\
\hline Pefloxacin & - & 4 & 0 & 1 & - & 4 & 0 & 1 & & 1 \\
\hline Praziquantel & 0.17 & 1 & - & 1 & - & 4 & 0 & 1 & 0.07 & 2 \\
\hline Spiramycin & 0.05 & 2 & 1322 & 3 & - & 4 & 0 & 1 & 0.29 & 3 \\
\hline Sulfachlorpyrazine & 0.05 & 2 & - & 1 & 30 & 3 & 0 & 1 & & 1 \\
\hline Sulfachlorpyridazine & 0.05 & 2 & 873 & 2 & 30 & 3 & 0 & 1 & 0.07 & 2 \\
\hline Sulfadiazine & 0.05 & 2 & 8487 & 3 & 30 & 3 & 1 & 2 & 0.51 & 3 \\
\hline Sulfadimethoxine & 0.05 & 2 & 1606 & 3 & 30 & 3 & 0 & 1 & 0.15 & 3 \\
\hline Sulfadoxine & 0.05 & 2 & 332 & 2 & 30 & 3 & 0 & 1 & & 1 \\
\hline Sulfaguanidine & 0.05 & 2 & 38 & 2 & 30 & 3 & 0 & 1 & & 1 \\
\hline Sulfamerazine & 0.05 & 2 & 219 & 2 & 30 & 3 & 0 & 1 & & 1 \\
\hline Sulfamethazine & 0.05 & 2 & 10,269 & 4 & 30 & 3 & 0 & 1 & 0.37 & 3 \\
\hline Sulfamethoxazole & 0.05 & 2 & 21,816 & 4 & 30 & 3 & 0 & 1 & 0.07 & 2 \\
\hline Sulfamethoxypyridazine & 0.05 & 2 & 219 & 2 & 30 & 3 & 0 & 1 & 0.15 & 3 \\
\hline Sulfamonomethoxine & 0.05 & 2 & 198 & 2 & 30 & 3 & 0 & 1 & & 1 \\
\hline Sulfaphenazole & 0.05 & 2 & - & 1 & 30 & 3 & 0 & 1 & & 1 \\
\hline Sulfaquinoxaline & 0.05 & 2 & 780 & 2 & 30 & 3 & 0 & 1 & & 1 \\
\hline Sulfasoxazole & 0.05 & 2 & - & 1 & 30 & 3 & 0 & 1 & & 1 \\
\hline Sulfathiazole & 0.05 & 2 & 22,902 & 4 & 30 & 3 & 0 & 1 & & 1 \\
\hline Tetracycline & 0.03 & 2 & 0 & 1 & - & 4 & 0 & 1 & 0.07 & 2 \\
\hline Thiamphenicol & 0.045 & 2 & 82 & 2 & 15 & 2 & 0 & 1 & & 1 \\
\hline Tiamulin & 0.03 & 2 & 13,598 & 4 & - & 4 & 0 & 1 & 0.07 & 2 \\
\hline Trimethoprim & 0.02 & 2 & 6614 & 3 & - & 4 & 1 & 2 & 2.2 & 4 \\
\hline
\end{tabular}


higher scores and, therefore, were selected as priority substances (Table 4).

The ADI value can be an indicator of safety of veterinary drugs. Among the veterinary drugs collected, four veterinary drugs including erythromycin had no ADI or had low values $(<0.001 \mathrm{mg} / \mathrm{kg}$ bw/day $)$, and therefore, they were assigned 4 points. The usage of drugs was as follows: oxytetracycline $>$ amoxicillin $>$ chlortetracycline $>$ florfenicol $>$ enrofloxacin. There were 17 veterinary drugs, including ceftiofur, which did not have a withdrawal period or had no set withdrawal period and, therefore, were assigned 4 points. When the usage was ranked by adding the scores of the number of sales and withdrawal period, enrofloxacin and tiamulin showed high values. Thus, frequently used veterinary drugs occupied a high proportion of those with high scores. In terms of residue occurrence, 4 points were assigned to a high number of noncompliant samples, and enrofloxacin showed the highest number of noncompliant samples (7 cases); thus, 4 points were assigned. Moreover, substances with the detection rate of $1 \%$ or more were assigned 4 points, and they included chlortetracycline and enrofloxacin (Table 3).

\section{Determination of risk-based priority}

Enrofloxacin (fluoroquinolone) had the highest score of 192. Enrofloxacin had 3 ADI points $(0.002 \mathrm{mg} / \mathrm{kg}$ bw/ day), a high value of usage $(40,668 \mathrm{~kg})$, and withdrawal period, and the highest number of noncompliant samples ( 7 cases). Enrofloxacin is used for the prevention and treatment of infection by pathogenic bacteria such as Vibriosis, and the amount of active ingredients is 100 $\mathrm{g} / \mathrm{kg}$ or L (NIFS 2016). In this study, enrofloxacin had high scores in potency, usage, and residue occurrence, and therefore, it was ranked high among the prioritized substances, but it was ranked low in the risk-based national residue program in Ireland. In the corresponding study, the use of enrofloxacin, in livestock products, was analyzed, and therefore, it was difficult to compare the results of the corresponding study with those of this study because of lack of sufficient information when used in fishery products (FSAI 2014). Next, the total score of amoxicillin was 108, indicating a high score among the investigated substances. In fact, amoxicillin, trimethoprim, and sulfadiazine among quartile (Q4) substances among the substances investigated in this study were shown to have high priority for management in consideration of frequency of use in the UK and toxicological results based on ADI (Capleton et al. 2006). Moreover, amoxicillin was shown to be a high-priority substance as a result of Ireland's national residue program monitoring, which was derived using the same formula as in this study. Oxolinic acid, trimethoprim, ciprofloxacin, florfenicol, and oxytetracycline were
Table 4 Risk-based ranking of veterinary drugs in aquatic products

\begin{tabular}{|c|c|c|c|}
\hline Substance & Score & Priority & Quartile \\
\hline Enrofloxacin & 192 & 1 & Q4 \\
\hline Amoxicillin & 108 & 2 & \\
\hline Oxolinic acid & 108 & 2 & \\
\hline Erythromycin & 96 & 4 & \\
\hline Trimethoprim & 84 & 5 & \\
\hline Ciprofloxacin & 75 & 6 & \\
\hline Florfenicol & 72 & 7 & \\
\hline Oxytetracycline & 70 & 8 & \\
\hline Nalidixic acid & 60 & 9 & \\
\hline Sulfadiazine & 60 & 9 & \\
\hline Spiramycin & 56 & 11 & Q3 \\
\hline Sulfamethazine & 56 & 11 & \\
\hline Chlortetracycline & 48 & 13 & \\
\hline Sulfadimethoxine & 48 & 13 & \\
\hline Tiamulin & 48 & 13 & \\
\hline Ceftiofur & 42 & 16 & \\
\hline Doxycycline & 42 & 16 & \\
\hline Sulfamethoxazole & 42 & 16 & \\
\hline Norfloxacin & 40 & 19 & Q2 \\
\hline Ofloxacin & 40 & 19 & \\
\hline Pefloxacin & 40 & 19 & \\
\hline Sulfamethoxypyridazine & 40 & 19 & \\
\hline Ormethoprim & 40 & 19 & \\
\hline Ampicillin & 36 & 24 & \\
\hline Flumequine & 32 & 25 & \\
\hline Difloxacin & 30 & 26 & \\
\hline Josamycin & 30 & 26 & \\
\hline Lincomycin & 30 & 26 & \\
\hline Sulfachlorpyridazine & 30 & 26 & \\
\hline Tetracycline & 30 & 26 & \\
\hline Sulfathiazole & 28 & 31 & \\
\hline Sulfadoxine & 20 & 32 & Q1 \\
\hline Sulfaguanidine & 20 & 32 & \\
\hline Sulfamerazine & 20 & 32 & \\
\hline Sulfamonomethoxine & 20 & 32 & \\
\hline Sulfaquinoxaline & 20 & 32 & \\
\hline Clindamycin & 16 & 37 & \\
\hline Sulfachlorpyrazine & 16 & 37 & \\
\hline Sulfaphenazole & 16 & 37 & \\
\hline Sulfasoxazole & 16 & 37 & \\
\hline Thiamphenicol & 16 & 37 & \\
\hline Praziquantel & 15 & 42 & \\
\hline Kitasamycin & 12 & 43 & \\
\hline Cefalexin & 6 & 44 & \\
\hline
\end{tabular}


mostly detected in fishery products in Korea, and the occurrence pattern was similar to the results of this study (Kang et al. 2018). Nalidixic acid had no number of sales but had higher priority than that of other compounds due to the detection rate and ADI. Our findings suggest that nalidixic acid can be used continuously in fishery products according to veterinarian prescription. On the contrary, cephalosporin-based cephalexin had the lowest score (total 6 points) because of a high ADI value and short withdrawal period. Cefalexin was also found to have a very low priority in the results.

\section{Applications of the study}

In this study, a risk-based approach was used to prioritize veterinary drugs used in fishery products for the development of new governmental risk management. The risk of veterinary drugs was ranked based on the risk-based approach by using the following three risk factors: (1) potency, (2) usage, and (3) residue occurrence. These factors were investigated based on the risk of the substances, priority was set up based on scientific grounds, and monitoring test was conducted, thereby increasing the efficiency of the national inspection priority. Ireland not only applies the priority of the substances to be tested to the actual national residue program using the risk-based priority in the calculation program but also uses it to estimate the minimum number of samples required for the monitored livestock products. To effectively accomplish the safety management of national residue substances, a risk-based prioritization program is necessary. As of May 2018, the Korea Food Code suggested simultaneous multi-residue method (50 substances) as a qualification method (MFDS 2019). However, it is difficult for an individual food safety lab to analyze all veterinary drugs including illegal use in terms of time and cost. Analyzing substances according to the priority presented in this study is expected to increase the efficiency of analysis in the food safety lab.

\section{Limitation of this study}

Risk-based priority has an uncertainty for each factor in the calculated model. Although the usage is calculated based on the data of veterinary drug sales, priority should be calculated by analyzing the actual dose of veterinary drugs used in aquatic products. In this study, we used the withdrawal period data according to veterinary drug guidebook for fishery products presented by the National Institute of Fisheries and Science. However, a low-cost intraperitoneal or intramuscular injection has recently been developed. Thus, the withdrawal period might differ with the administration route (injection and oral). Additionally, in 2016-2018, the MRLs were updated by the Korean regulation. Ceftiofur, trichlorfone, and ethoxyquin were updated by the Korean Food Code.
Thus, newly generated data need constant updating through a web-based system. Lastly, carryover from feed to food of unavoidable and unintended residues of veterinary drugs and pesticides should be added in risk-based priority for the national residue program.

\section{Conclusions}

This study can be applied to the prioritization of monitoring and safety management of veterinary drugs in fishery products, and it can be actively utilized in the establishment of future national residue programs and domestic food re-inspection system in fishery products. In the future, dataset and equation for all factors of the risk-based approach should be updated in newly developed web-based system.

\section{Abbreviations}

ADI: Acceptable daily intakeEMAEuropean Medicine AgencyFSAIFood Safety Authority IrelandJECFAJoint Expert Committee of Food AdditivesKAHPAKorea Animal Health Products AssociationMRLMaximum residue limits

\section{Acknowledgments}

Hui-Seung Kang and Songyi Han contributed equally to this work.

\section{Authors' contributions}

The authors contributed to this manuscript as follows: H-S K. studied the design, data analysis, and writing of the manuscript; SY H. contributed the writing of the manuscript and drafting of the manuscript; B-H C. reviewed the manuscript; and HJ L. studied the design and data analysis. All authors reviewed, edited, and approved the manuscript for submission.

\section{Funding}

This work was supported by the Ministry of Food and Drug Safety, republic of Korea (Grant Number 18162MFDS521) in 2018-2019 and 19161MFDS581 in 2019.

\section{Availability of data and materials}

The datasets used and/or analyzed during the current study are available from the corresponding author on reasonable request.

\section{Consent for publication}

Not applicable

\section{Competing interests}

The authors declare that they have no competing interests.

\section{Author details}

${ }^{1}$ Pesticide and Veterinary Drugs Residue Division, National Institute of Food and Drug Safety Evaluation, Osong, Cheongju, Chungcheongbuk-do 361-709, Republic of Korea. ${ }^{2}$ Food Contaminants Division, National Institute of Food and Drug Safety Evaluation, Osong, Cheongju, Chungcheongbuk-do 361-709, Republic of Korea. ${ }^{3}$ CHEM.I.NET Ltd., Room 302, 773-3, Mok-dong,

Yangcheon-gu, Seoul, South Korea.

Received: 30 July 2019 Accepted: 12 November 2019

Published online: 12 December 2019

\footnotetext{
References

Almeida A, Duarte S, Nunes R, Rocha H, Pena A, Meisel L. Human and veterinary antibiotics used in Portugal_-a ranking for ecosurveillance. Toxics. 2014;2(2): $188-225$.

Capleton AC, Courage C, Rumsby P, Holmes P, Stutt E, Boxall AB, Levy LS. Prioritising veterinary medicines according to their potential indirect human exposure and toxicity profile. Toxicol Lett. 2006;163(3):213-23.

Danaher M, Shanahan C, Butler F, Evans R, O'Sullivan D, Glynn D, Camon T, Lawlor P, O'Keeffe M. Risk-based approach to developing a national residue sampling plan for testing under European Union regulation for veterinary
} 
medicinal products and coccidiostat feed additives in domestic animal production. Food Addit Contam Part A. 2016;33(7):1155-65.

Di Nica V, Menaballi L, Azimonti G, Finizio A. RANKVET: a new ranking method for comparing and prioritizing the environmental risk of veterinary pharmaceuticals. Ecol Indicators. 2015;52:270-6.

FAO. The State of World Fisheries and Aquaculture 2016. Food and Agriculture Organization of the United Nations. Retrieved from https://www.fao.org/ publications. Accessed 1 July 2019.

FSAl. Risk-based approach to developing the national residue sampling plan, Food safety Authority of Ireland. 2014, Retrieved from https://www.fsai.ie/ publications_riskbased_residue_sampling. Accessed 1 July 2019.

KAHPA. Korea animal health product association statistics. Retrieved from http:// www.kahpa.or.kr/ENG/ Accessed 1 July 2019. (2019)

Kang H-S, Kwon NJ, Jeong J, Lee K, Lee H. Web-based Korean maximum residue limit evaluation tools: an applied example of maximum residue limit evaluation for trichlorfon in fishery products. Environ Sci Pollut Res. 2019; 26(7):7284-99.

Kang H-S, Lee S-B, Shin D, Jeong J, Hong J-H, Rhee G-S. Occurrence of veterinary drug residues in farmed fishery products in South Korea. Food Control. 2018; 85:57-65.

Kim H-Y, Chung S-Y, Choi S-H, Lee J-S, Choi I-S, Cho M-J, Shin M-S, Song J-S, Choi $\mathrm{J}-\mathrm{C}$, Park H-O. Monitoring of veterinary drug residues in foods produced in Korea. Kor J Food Sci Technol. 2010;42(6):653-63.

Kim J, Shin D, Kang H-S, Lee E, Choi SY, Lee H-S, Cho BH, Lee KB, Jeong J. Determination of ceftiofur residues by simple solid phase extraction coupled with liquid chromatography-tandem mass spectrometry in eel, flatfish, and shrimp. Mass Spectrometry Lett. 2019;10(2):43-9.

Kim JW, Cho MY, Jee B-Y, Park M, Kim NY. Administration and use of aquaculture drugs in Korea. J Fish Pathol. 2014;27(1):67-75.

Lee HJ, Cho SH, Shin D, Kang HS. Prevalence of antibiotic residues and antibiotic resistance in isolates of chicken meat in Korea. Korean J Food Sci Anim Resour. 2018;38(5):1055-63.

MFDS. Korean food standard code. Ministry of Food and Drug Safety 2019, Retrieved from: https://www.mfds.go.kr/eng/index.do. Accessed 1 July 2019.

NIFS. National Institution of Fisheries Science - NIFS. (2016). Korean aquatic medicine catalog. Retrieved from https://www.nifs.go.kr/fishguard/ medicine03. Accessed 1 July 2019.

Shin D, Kang H-S, Jeong J, Kim J, Choe WJ, Lee KS, Rhee G-S. Multi-residue determination of veterinary drugs in fishery products using liquid chromatography-Tandem mass spectrometry. Food Analytic Methods. 2018, 11(6):1815-31.

Uchida K, Konishi Y, Harada K, Okihashi M, Yamaguchi T, Do MHN, Thi Bui L, Duc Nguyen T, Do Nguyen $P$, Thi Khong D. Monitoring of antibiotic residues in aquatic products in urban and rural areas of Vietnam. J Agric Food Chem. 2016;64(31):6133-8

\section{Publisher's Note}

Springer Nature remains neutral with regard to jurisdictional claims in published maps and institutional affiliations.

Ready to submit your research? Choose BMC and benefit from:

- fast, convenient online submission

- thorough peer review by experienced researchers in your field

- rapid publication on acceptance

- support for research data, including large and complex data types

- gold Open Access which fosters wider collaboration and increased citations

- maximum visibility for your research: over $100 \mathrm{M}$ website views per year

At $\mathrm{BMC}$, research is always in progress.

Learn more biomedcentral.com/submissions 